\title{
Curative Resection of Double Primary Lung Cancer after 15-Month Bortezomib Administration
}

\author{
Hiroya Tamaki $^{a} \quad$ Masaki Hashimoto $^{b}$ Yoshiro Naito $^{c}$ Masaaki Lee-Kawabata ${ }^{c}$ \\ ${\text { Tohru Masuyamac }{ }^{c} \text { Hiroyasu Ogawa }^{a} \text { Seiki Hasegawa }}^{b}$
}

aDepartment of Internal Medicine, Division of Hematology,

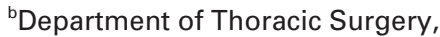

'Department of Internal Medicine, Cardiovascular Division, Hyogo College of Medicine, Nishinomiya, Japan

Early detection combined with surgical resection remains the gold standard of curative treatment for stage I non-small cell lung cancer (NSCLC) [1]. High-risk surgical candidates require effective alternatives to surgery to prevent tumor growth and lymph node metastasis. We present herein a case of successful operation after bortezomib administration in a patient with stage I NSCLC, in whom surgery had to be deferred for 15 months because of the treatment required for cardiac failure due to multiple myeloma-associated immunoglobulin light-chain (AL) amyloidosis.

A 63-year-old Japanese man who had never smoked was diagnosed with stage I lung cancer, as confirmed from bronchial washing specimens positive for malignancy, only in the right upper lobe. Chest computed tomography (CT) scans showed a 40-mm ground-glass opacity in the right upper lobe and a $12-\mathrm{mm}$ ground-glass opacity in the right lower lobe, suggestive of double primary lung cancer (fig. 1). However, the life expectancy of the patient was less than 6 months because of symptomatic cardiac AL amyloidosis, treatment for which was prioritized over tumor resection. After administration of bortezomib plus dexamethasone for 15 months, cardiac function markedly improved after achievement of a hematological response with regard to the AL amyloidosis, as previously reported [2]. The 2 ground-glass opacities on chest CT showed almost no change in size compared to their appearance before 15 months (fig. 1). Positron emission tomography/CT (PET/CT) showed no 18-fluorodeoxyglucose uptake in these lesions either before or after bortezomib treatment. A work-up with 18-fluorodeoxyglucose PET/CT revealed no metastasis. All other organ evaluations showed normal function. Therefore, we considered the patient a candidate for surgery, and could safely perform right upper lobectomy and right lower partial resection with mediastinal lymphadenectomy. Postoperative evaluation confirmed double primary well differentiated lung cancer with adenocarci- noma, mixed subtype, in the right $\mathrm{S} 1$, and brochioloalveolar carcinoma in the right S6 segment, respectively. Both tumors were completely resected with negative margins (pT2aN0M0 and pT1aN0M0). There was no apparent effect of bortezomib therapy on the tumor specimens. The patient remains in complete remission and good health, as noted on follow-up 15 months after the operation. For treatment of AL amyloidosis, he continues to receive bortezomib at $0.7 \mathrm{mg} / \mathrm{m}^{2}$, reduced from twice per month to once monthly since 10 months after the operation.

Neoadjuvant therapy such as preoperative chemotherapy has been reported to significantly improve the overall survival of patients with operable NSCLC, including patients with

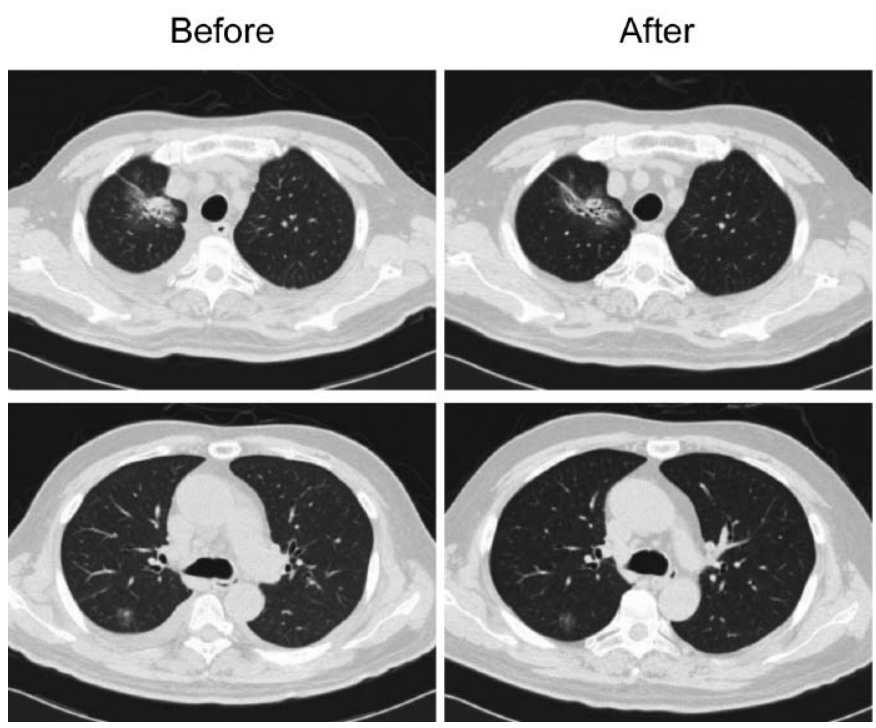

Fig. 1. Chest computed tomography images before and after 15 months of bortezomib therapy. Ground-glass opacities are seen in the right upper and lower lung in the upper and lower panels, respectively.

\begin{tabular}{ll}
\hline KARGER & $\begin{array}{l}\text { (1) 2012 S. Karger GmbH, Freiburg } \\
0378-584 X / 12 / 0354-0216 \$ 38.00 / 0\end{array}$ \\
$\begin{array}{l}\text { Fax +49 761 4520714 } \\
\text { Information@Karger.de } \\
\text { www.karger.com }\end{array}$ & $\begin{array}{l}\text { Accessible online at: } \\
\text { www.karger.com/onk }\end{array}$
\end{tabular}

Hiroya Tamaki, MD, PhD

Division of Hematology, Department of Internal Medicine

Hyogo College of Medicine

1-1 Mukogawa-cho, Nishinomiya City, Hyogo 663-8501, Japan

Tel. +81 798 45688-6, Fax -7

tamakhi@hyo-med.ac.jp 
stage III NSCLC [3, 4]. Bortezomib is a specific proteasome inhibitor to affect the ubiquitin-proteasome pathway that plays a central role in the targeted destruction of many intracellular proteins, and has achieved greatest efficacy in the treatment of refractory multiple myeloma. As one of the mechanisms of action in NSCLC cells, bortezomib inhibits nuclear factor- $\kappa \mathrm{B}(\mathrm{NF}-\kappa \mathrm{B})$ signaling by blocking degradation

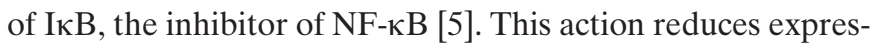
sion levels of proinflammatory response genes and upregulates cyclin-dependent kinase inhibitors, which results in reduced growth and increased apoptosis. In advanced NSCLC, it remains debatable whether bortezomib can exert inhibitory activity alone, or synergistic effects in combination with other chemotherapeutic agents $[5,6]$. Of course, the present case does not mean that bortezomib could maintain operable tumor stages for 15 months, since NSCLC can exhibit slow growth. Preoperative bortezomib administration, however, enabled safe and successful surgical treatment of this patient with multiple myeloma-associated cardiac AL amyloidosis and concurrent double primary NSCLC, without increased risk of intra- and postoperative complications.

\section{Disclosure Statement}

There is no potential conflict of interest.

\section{References}

1 Hanagiri T, Baba T, So T, Yasuda M, Sugaya M, Ono K, Uramoto H, Takenoyama M, Yasumoto K: Time trends of surgical outcome in patients with non-small cell lung cancer. J Thorac Oncol 2010; 5:825-829.

2 Tamaki H, Naito Y, Lee-Kawabata M, Taniguchi Y, Hao H, Hirota S, Hasegawa S, Masuyama $T$, Ogawa H: Sustained improvement in cardiac function with persistent amyloid deposition in a patient with multiple myeloma-associated cardiac amyloidosis treated with bortezomib. Int J Hematol 2010; 92:655-658
3 Song WA, Zhou NK, Wang W, Chu XY, Liang CY, Tian XD, Guo JT, Liu X, Liu Y, Dai WM: Survival benefit of neoadjuvant chemotherapy in non-small cell lung cancer: an updated meta-analysis of 13 randomized control trials. J Thorac Oncol 2010;5:510-516.

4 Weder W, Collaud S, Eberhardt WE, Hillinger S, Welter S, Stahel R, Stamatis G: Pneumonectomy is a valuable treatment option after neoadjuvant therapy for stage III non-small-cell lung cancer. J Thorac Cardiovasc Surg 2010;139:1424-1430.
5 Escobar M, Velez M, Belalcazar A, Santos ES, Raez LE: The role of proteasome inhibition in nonsmall cell lung cancer. J Biomed Biotechnol 2011;2011:806506

6 Li T, Ho L, Piperdi B, Elrafei T, Camacho FJ, Rigas JR, Perez-Soler R, Gucalp R: Phase II study of the proteasome inhibitor bortezomib (PS-341, Velcade) in chemotherapy-naive patients with advanced stage non-small cell lung cancer (NSCLC). Lung Cancer 2010;68:89-93. 